\title{
Obstetric outcome in pregnancy with thrombophilia: a comparative study of two different thromboprophylaxis regimes
}

\author{
Shilpa Asthana ${ }^{1 *}$, Bandana Sodhi ${ }^{2}$, Satish Kumar ${ }^{3}$ \\ ${ }^{1}$ Department of Obstetrics and Gynecology, INHS Asvini, Mumbai, Maharashtra, India \\ ${ }^{2}$ Department of Obstetrics and Gynecology, Moolchand Medcity, New Delhi, India \\ ${ }^{3}$ Pathology and Transfusion Medicine, Armed Forces Transfusion Centre, Delhi Cant, New Delhi, India
}

Received: 18 June 2017

Accepted: 19 July 2017

*Correspondence:
Dr. Shilpa Asthana,
E-mail: asthanashilpa @gmail.com

Copyright: ( ) the author(s), publisher and licensee Medip Academy. This is an open-access article distributed under the terms of the Creative Commons Attribution Non-Commercial License, which permits unrestricted non-commercial use, distribution, and reproduction in any medium, provided the original work is properly cited.

\begin{abstract}
Background: Thrombophilia in pregnancy is a leading cause of both maternal and fetal mortality and morbidity. Thromboprophylaxis is administered to the patients with thrombophilia with an aim to improve the obstetric outcome. Although various studies have proven the benefits of treating pregnant women with thrombophilia, few studies comparing the usage of Unfractionated Heparin (UFH) and Low Molecular Weight Heparin (LMWH) along with low - dose ecosprin in terms of obstetric outcome, incidence of IUGR, pre-eclampsia, mode of delivery, neonatal birth weight and adverse effects of therapy have been published. This study was undertaken to compare two different treatment modalities using either UFH or LMWH (along with low dose ecosprin) in pregnant patients with thrombophilia with respect to obstetric outcomes and incidence of adverse effects of therapy.

Methods: This randomised, prospective study was conducted in patients with a previous history of recurrent pregnancy losses or previous adverse pregnancy outcomes. Sixty patients diagnosed with thrombophilia were randomly divided into two groups of 30 patients each (Group I and II). Patients in Group I received Inj Unfractionated Heparin 5000 I.U. (s.c) twice daily and Tab Ecosprin $75 \mathrm{mg}$ once daily and those in Group II received Inj LMWH (enoxaparin) $40 \mathrm{mg}$ (s.c) once daily and Tab Ecosprin $75 \mathrm{mg}$ once daily. These pregnancies were followed and the obstetrical outcome was determined. The data collected was analysed using the Student's 't test and Chi-square test. P values $<0.05$ were considered statistically significant.

Results: There was no significant difference observed between two treatment groups with respect to pregnancy outcomes, incidence of IUGR, pre-eclampsia and mode of delivery (vaginal or by caesarean section). Treatment with a combination of LMWH and ecosprin administered to patients in Group II resulted in significantly higher neonatal birth weights.

Conclusions: Treatment with a combination of LMWH and ecosprin resulted in significantly higher neonatal birth weights as compared to a regime that comprised of UFH and ecosprin. There was no significant difference seen in patients who were treated with either UFH or LMWH along with low dose ecosprin in terms of obstetric outcome, incidence of IUGR, pre-eclampsia and mode of delivery. No thromboembolic events or side effects were witnessed in patients subjected to either of the two regimes using LMWH or UFH with low dose ecosprin, thus, highlighting the safety of the antithrombotic therapy during pregnancy as used in this study.
\end{abstract}

Keywords: Anti-phospholipid antibody syndrome, Ecosprin, LMWH, Obstetric outcome, Recurrent pregnancy loss, UFH, Thrombophilia, Thromboprophylaxis 


\section{INTRODUCTION}

Thrombophilia in pregnancy is a leading cause of both maternal and fetal mortality and morbidity. ${ }^{1}$ The pregnancy is a hypercoaguable state. ${ }^{2-5}$ It has been postulated that due to stasis, disruption of the vessel wall and hypercoaguability (Virchow Triad 1856), pregnant women are more prone for venous thromboembolic events..$^{2-5}$

The thrombotic events are not only restricted to venous thromboembolism but also can cause repeated embryonic loss, fetal demise and other adverse pregnancy outcomes due placental insufficiency or thrombosis. ${ }^{4-7}$

Pregnant women with thrombophilia carry a greater risk than non-pregnant women for an adverse obstetric outcome. ${ }^{4,8}$

Thrombophilia may be inherited or acquired..$^{9}$ The pregnancy outcome measures have been found to improve following administration of heparin and ecosprin. ${ }^{3,4,8,10,11}$

\section{METHODS}

After ethical committee clearance, sixty antenatal patients with thrombophilia attending the antenatal clinic at a large, tertiary teaching hospital were included in this study. The inclusion criteria of bad obstetric history were defined as follows:

\section{Inclusion criteria}

- history of at least one unexplained fetal demise at or beyond 10 weeks of gestation

- at least three unexplained consecutive spontaneous abortions before 10 weeks of gestation

- at least one pre-term birth before 34 weeks of gestation because of eclampsia or severe preeclampsia or placental insufficiency

- history of vascular (arterial/venous) thrombosis.

\section{Exclusion criteria}

- pregnant patients without risk factors or bad obstetric history

- pregnant patients with multi-fetal gestation, gestational diabetes, abnormal uterine morphology, auto - immune disease.

The tests used for confirming the diagnosis were as follows: Acquired thrombophilia:

- Anti-cardiolipin antibodies (ACA) - by ELISA technique, expressed as ACA IgG, ACA - IgM.

- Lupus anticoagulant - tested by Kaolin clotting time as screening test and ELISA technique.
Inherited thrombophilia: Samples were analysed in a fully automated coagulometer (Stago) for inherited thrombophilia. Tested by determining Protein C, Protein S, APCR, antithrombin III and homocystein levels by ELISA technique.

The patients were randomly divided into two groups of 30 each and designated as follows:

- Treatment Group I: This group comprised of patients treated with tablet ecosprin $75 \mathrm{mg}$, orally as once daily dose (OD) along with injection unfractionated heparin (UFH) 5000IU subcutaneously (s.c), twice daily (BD).

- Treatment Group II: This group consisted of patients treated with tablet ecosprin $75 \mathrm{mg}$, orally as once daily dose (OD) along with injection low molecular weight heparin (LMWH), enoxaparin $40 \mathrm{mg}$ subcutaneously (s.c), once daily (OD).

Ecosprin and heparin (LMWH or UFH) were started on confirmation of pregnancy. Ecosprin was stopped at 36 weeks period of gestation.

Unfractionated heparin and low molecular weight heparin were discontinued at 24 hours prior to labour induction. Thromboprophylaxis was continued for 06 weeks postpartum in all patients. The primary outcome measure included was: pregnancy outcome (live births) - term or preterm births.

The secondary outcome measures evaluated were: incidence of pregnancy associated complications-IUGR, pre-eclampsia, abruptio placenta or a combination of both; thromboembolic events- deep vein thrombosis, pulmonary embolism, stroke, transient ischemic attack; the route of delivery-vaginal / caesarean delivery; potential side effects of antithrombotic therapy (Heparin+Ecosprin) on both the mother and the fetus; birth weight of neonates in the two groups. Feto-maternal evaluations that were undertaken during the course of the study included complete haemogram and coagulation profile every four weeks, obstetric ultrasound with color doppler velocimetry at $16,20,24,28,32,36$ weeks to access uteroplacental blood flow, fetal weight gain and fetal well-being.

\section{Statistical analysis}

The statistical analysis was done using Student's ' $t$ ' test and Chi square analysis with $\mathrm{p}$ value $<0.05$ taken as statistically significant.

\section{RESULTS}

There was no significant difference between two treatment groups with respect to pregnancy outcomes with respect to preterm or term delivery and abortions (Table 1). In fact, treatment with either preparation of heparin resulted in live births. 
Table 1: Pregnancy outcome in the two study groups.

\begin{tabular}{|lllll|}
$\begin{array}{l}\text { Treatment } \\
\text { groups }\end{array}$ & $\begin{array}{l}\text { Pregnancy outcome } \\
\text { Preterm } \\
\text { (live } \\
\text { births) }\end{array}$ & $\begin{array}{l}\text { Term } \\
\text { (live } \\
\text { births) }\end{array}$ & Abortion & Total \\
\hline I & $0(0)$ & $29(48.33)$ & $1(1.67)$ & $30(50)$ \\
\hline II & $1(1.67)$ & $29(48.33)$ & $0(0)$ & $30(50)$ \\
\hline Total & $1(1.67)$ & $58(96.66)$ & $1(1.67)$ & $60(100)$ \\
\hline
\end{tabular}

$\chi^{2}=2, \mathrm{P}>0.05$. Figures depicted indicate number of cases and figures in brackets represent percentage of a total of 60 cases. Patients in Group I was treated with Inj Unfractionated Heparin 5000 IU sc and Tab Ecosprin 75mg OD. Those in Group IIreceived Inj LMWH (enoxaparin) $40 \mathrm{mg} s \mathrm{OD}$ and Tab Ecosprin $75 \mathrm{mg}$ OD.

Table 2: IUGR in study groups.

\begin{tabular}{|llll|}
\hline $\begin{array}{l}\text { Treatment } \\
\text { groups }\end{array}$ & $\begin{array}{l}\text { IUGR } \\
\text { Present }\end{array}$ & Absent & Total \\
\hline I & $5(8.33)$ & $25(41.67)$ & $30(50)$ \\
\hline II & $2(3.33)$ & $28(46.67)$ & $30(50)$ \\
\hline Total & $7(11.66)$ & $53(88.33)$ & $60(100)$ \\
\hline
\end{tabular}

$\chi^{2}=0.65, \mathrm{P}>0.05$; IUGR, intra-uterine growth restriction. Figures depicted indicate number of cases and figures in brackets represent percentage of a total of 60 cases. Treatment Group I: Inj Unfractionated Heparin 5000 IU sc BD+Tab Ecosprin 75mg OD. Treatment Group II: Inj LMWH (enoxaparin) $40 \mathrm{mg} \mathrm{sc}$ OD + Tab Ecosprin $75 \mathrm{mg}$ OD.

Although in Group II (LMWH + Ecosprin) number of cases of IUGR was less than Group I (Unfractionated heparin + Ecosprin), but statistically this difference was insignificant (Table 2). There was no significant difference between two treatment groups with respect to incidence of preclampsia (Table 3).

Table 3: Preeclampsia in study groups.

\begin{tabular}{|llll|}
\begin{tabular}{llll|} 
Treatment \\
groups
\end{tabular} & $\begin{array}{l}\text { Preeclampsia } \\
\text { Present }\end{array}$ & Absent & Total \\
\hline I & $3(5)$ & $27(45)$ & $30(50)$ \\
\hline II & $5(8.33)$ & $25(41.67)$ & $30(50)$ \\
\hline Total & $8(13.33)$ & $52(86.67)$ & $60(100)$ \\
\hline
\end{tabular}

$\chi^{2}=1.29, \mathrm{P}>0.05$. Figures depicted indicate number of cases and figures in brackets represent percentage of a total of 60 cases. Treatment Group I: Inj UFH 5000 IU sc BD+Tab Ecosprin 75mg OD. Treatment Group II: Inj LMWH (enoxaparin) $40 \mathrm{mg} \mathrm{sc}$ OD + Tab Ecosprin $75 \mathrm{mg}$ OD.

Table 4: Mode of delivery in the study groups.

\begin{tabular}{|c|c|c|c|}
\hline \multirow{2}{*}{$\begin{array}{l}\text { Mode of } \\
\text { delivery }\end{array}$} & \multicolumn{2}{|c|}{ Treatment groups } & \multirow{2}{*}{ Total } \\
\hline & I & II & \\
\hline Vaginal & $24(40.68)$ & $21(35.59)$ & $45(76.27)$ \\
\hline LSCS & $5(8.47)$ & $9(15.25)$ & $14(23.73)$ \\
\hline Total & $29(49.15)$ & $30(50.85)$ & $59(100)$ \\
\hline
\end{tabular}

$\chi^{2}=0.71, \mathrm{P}>0.05$. Figures depicted indicate number of cased and figures in brackets represent percentage of a total of 60 cases. Treatment Group I: Inj UFH 5000 IU sc BD+Tab Ecosprin $75 \mathrm{mg}$ OD. Treatment Group II: Inj LMWH (enoxaparin) $40 \mathrm{mg} \mathrm{sc}$ OD + Tab Ecosprin 75 mg OD.
Maximum number of cases i.e. 45 patients (24 patients in Group I and 21 patients in Group II) delivered vaginally while 14 patients underwent caesarean section (5 patients in Group I and 9 patients in Group II). The route of delivery was not influenced or affected by the two treatment modalities offered to the study groups. There was no significant difference between the percentage of caesarean delivery and vaginal delivery between the two treatment groups (Table 4).

Patients in Group II (LMWH+Ecosprin) had higher birth weight neonates when compared to Group I (Unfractionated heparin+Ecosprin) (Table 5).

Table 5: Comparison of birth weights in study groups.

\begin{tabular}{|c|c|c|c|c|}
\hline \multirow{2}{*}{$\begin{array}{l}\text { Birth weight } \\
\text { (Kg) }\end{array}$} & \multicolumn{2}{|c|}{ Treatment groups } & \multirow{2}{*}{$\begin{array}{l}\mathrm{Z} \\
\text { test }\end{array}$} & \multirow{2}{*}{$\begin{array}{l}P \\
\text { Value }\end{array}$} \\
\hline & I $(\mathbf{n}=\mathbf{2 9})$ & II $(\mathbf{n = 3 0})$ & & \\
\hline Mean \pm SD & $2.43 \pm 0.29$ & $2.69 \pm 0.30$ & 3.52 & $<0.0001$ \\
\hline
\end{tabular}

\section{DISCUSSION}

A wide range of therapies have been studied for thrombophilia that range from no treatment to low dose ecosprin only regimes, low dose ecosprin with unfractionated heparin, low dose ecosprin with low molecular weight heparin, steroids and immunoglobulin. ${ }^{3,4,8,10-12} \quad$ Various multi-centric randomised trials and studies have been undertaken and heparin along with low dose ecosprin has been preferred as thromboprophylaxis in pregnant women with thrombophilia. ${ }^{3,4,8,10-12}$ It has also been seen that the treatment with LMWH has been preferred to unfractionated heparin. . $^{3,8,811,13-20}$ The recommendations for anticoagulation therapy for acquired thrombophilia are very well defined and have found to have a significant positive impact on pregnancy outcome. . $^{2,8,12,15,22,23}$

Heparin is a glycosaminoglycan that binds to antithrombin thereby inactivating thrombin, Factor IXa and Factor Xa resulting in expression of anticoagulant response. Heparin prevents occurrence of arterial, venous thrombotic events and also thrombosis that occurs in microcirculation-the decidual trophoblast interface is of prime importance with respect to impact on pregnancy outcomes. There are two types of heparin that have been studied extensively for the purpose of thromboprophylaxis in pregnant women with thrombophilia, viz, unfractionated heparin and low molecular weight heparin. Unfractionated heparin has a half-life of 30 minutes with dosage administration 2-3 times a day. Its anticoagulant response is quite variable. Low molecular weight heparin has a half-life of 03 hours with a frequency of administration 1-2 times a day. Its bioavailability is better than that of unfractionated heparin. The ease of administration and better bioavailability of low molecular weight heparin has 
resulted in conduct of various trials favouring its use over unfractionated heparin in treatment of pregnant women with thrombophilia. ${ }^{3,4,8,13-20}$

Low dose ecosprin acts by blocking the conversion of arachdonic acid to thromboxane $\mathrm{A}_{2}$. Hence, there is reduction in synthesis of Thromboxane $A_{2}$. This prevents vasoconstriction and platelet aggregation. Although anticoagulation can be initiated with either unfractionated or low molecular weight heparin in pregnancy, recent guidelines by American College of Chest Physicians suggest preferential use of low molecular weight heparin during pregnancy because of better bioavailability, longer plasma half- life, a greater predictable dose response, lesser risk of thrombocytopenia and osteoporosis, and the need for less frequent dosing. ${ }^{8}$ However, unfractionated heparin may be considered in low resource settings or when low molecular heparin is not available for use. In this study 42 patients were diagnosed with acquired thrombophilia, 14 patients with inherited thrombophilia and 04 patients with both inherited and acquired thrombophilia. Hence, the highest percentages of women were found to have acquired thrombophilia as a causative factor for previous pregnancy losses.

Based on the obstetric history obtained by the patients included in this study, there were 93 instances of previous pregnancy losses in the first trimester, 30 pregnancy losses in the second trimester and 13 intrauterine fetal demises (IUFDs). No history suggestive of venous thromboembolism in previous pregnancy was reported by any of the patients included in this study. None of the patients included in this study received thromboprophylaxis in previous pregnancy. The patients with either acquired or inherited thrombophilia had comparable number of live births after treatment in both the treatment groups in this study. The role of antiphosholipid antibody syndrome and recurrent pregnancy losses has been well established in various randomised control trials as is evident in our study also. ${ }^{8,24-27}$

Amongst the 60 patients included in our study group, 58 patients had term delivery, 01 patient had preterm delivery and 01 patient had abortion at 14 weeks period of gestation. This is in consonance with the findings of other studies that have shown that administration of heparin and ecosprin has improved the obstetric outcome in patients with thrombophilia. ${ }^{3,4,8,10,11}$ The placental vascular pathology - Intrauterine growth restriction, preeclampsia and combination of the two which occurred despite the therapy to pregnant women in both study groups resulted in a live birth. There was no statistically significant difference between two treatment groups with respect to incidence of preeclampsia and intrauterine growth restriction. The mode of delivery was not influenced by the two treatment modalities offered to the study group. Out of the 60 patients in the study group 45 patients delivered vaginally while 14 patients underwent caesarean section and 01 aborted at 14 weeks period of gestation. Treatment group II (LMWH+Ecosprin) had higher birth weight neonates when compared to treatment group I (Unfractionated heparin+Ecosprin).

Irrespective of the two treatment protocols used in the study, no case of abruptio placenta, late fetal demise or neonatal demise was observed. Hence, thromboprophylaxis administered to pregnant women with thrombophilia resulted in positive neonatal outcomes. There was no evidence of thromboembolic complications during the therapy in the pregnant women with thrombophilia such as deep vein thrombosis, pulmonary embolism, stroke or transient ischaemic attack in either treatment groups. The adverse effects of the drug like cutaneous manifestations, minor bleeding episodes such as epistaxis, bleeding from the gums, haematuria and thrombocytopenia were not witnessed in any of the two treatment groups. When the outcome of previous untreated pregnancies is compared to that of treated pregnancies with the anticoagulants in this study, the positive obstetric outcome with therapy is evident. The authors acknowledge that the relatively small sample size of 60 patients used in the study may be inadequately powered to unequivocally establish the comparison between the treatment modalities used in this study. Nevertheless, this study could be the basis of further research in this field towards formulation of larger, multicentric randomized controlled trials involving Indian population in future.

\section{CONCLUSION}

Present study has proven the benefit of thromboprophylaxis in obstetric outcomes in patients with both acquired and inherited thrombophilia. The pregnant women with thrombophilia in this study have benefitted from both unfractionated heparin and low molecular weight heparin. The superiority of LMWH over Unfractionated Heparin in terms of live births - term or preterm births, IUGR, pre - eclampsia, abruptio placenta, thromboembolic events, route of delivery has not been established although patients treated with LMWH were seen to have higher birth weights in our study.

The known adverse effects of the drugs administered in this study such as cutaneous manifestations, minor bleeding episodes such as epistaxis, bleeding from the gums, haematuria and thrombocytopenia were not witnessed in any of the two treatment groups thereby highlighting the safety of thromboprophylaxis in the dosages administered. However, larger multi-centric, randomised controlled trials are needed to fully establish the findings of this study in the context of Indian population.

\author{
Funding: No funding sources \\ Conflict of interest: None declared \\ Ethical approval: The study was approved by the \\ Institutional Ethics Committee
}




\section{REFERENCES}

1. Simcox LE, Ormesher L, Tower C, Greer 1A. Thrombophilia and Pregnancy Complications. Int J Mol Sci. 2015;16(12):28418-28.

2. Battinelli EM, Marshall A, Connors JM. The role of thrombophilia in pregnancy. Thrombosis. 2013;2013.

3. James A; Committee on Practice Bulletins-Obstetrics. Practice bulletin no. 123: thromboembolism in pregnancy. Obstet Gynecol. 2011 Sep;118(3):718-29.

4. Bennett SA, Bagot CN, Arya R. Pregnancy loss and thrombophilia: the elusive link. $\mathrm{Br} \mathrm{J}$ Haematol. 2012;157(5):529-42.

5. Sultan AA, West J, Tata LJ, Fleming KM, NelsonPiercy C, Grainge MJ. Risk of first venous thromboembolism in and around pregnancy: a population based cohort study. $\mathrm{Br} \mathrm{J}$ Haematol. 2012;156(3):366-73.

6. Pabinger I. Thrombophilia and its impact on pregnancy. Thromb Res. 2009;123 Suppl 3:S16-S21.

7. Middeldorp S. Thrombophilia and pregnancy complications: cause or association? J Thromb Haemost. 2007;5 Suppl 1:276-282.

8. Bates SM, Greer IA, Middeldorp S, Veenstra DL, Prabulos AM, Vandvik PO. VTE, thrombophilia, antithrombotic therapy, and pregnancy: antithrombotic therapy and prevention of thrombosis: American College of Chest Physicians evidence-based clinical practice guidelines. Chest. 2012;141(2):e691S-736S.

9. Pierangeli SS, Leader B, Barilaro G, Willis R, Branch DW. Acquired and inherited thrombophilia disorders in pregnancy. Obstet Gynecol Clin North Am. 2011;38(2):271-95.

10. Lockwood C. Thrombosis, thrombophilia, and thromboembolism: clinical updates in women are health care. ACOG. 2007;6(4).

11. Kher A, Bauersachs R, Nielsen JD. The management of thrombosis in pregnancy: role of LMWH. Thromb Haemost. 2007;97(4):505-13.

12. Xiao J, Xiong J, Zhu F, He L. Effect of prednisone, aspirin, low molecular weight heparin and intravenous immunoglobulin on outcome of pregnancy in women with antiphospholipid syndrome. Exp Therapeu Med. 2013;5(1):287-91.

13. Potdar N, Gelbaya TA, Konje JC, Nardo LG. Adjunct low-molecular-weight heparin to improve live birth rate after recurrent implantation failure: a systematic review and meta-analysis. Hum Reprod Update. 2013;19(6):674-84.

14. DeVries JIP, VanPampus MG, Hague WM, Bezemer PD, Joosten JH. On behalf of FRUIT Investigators. Low-molecular-weight heparin added to aspirin in the prevention of recurrent early-onset pre-eclampsia in women with inheritable thrombophilia: the FRUITRCT. J Thromb Haemost. 2012;10:64-72.
15. American College of Obstetricians and Gynecologists: Practice Bulletin No. 132: antiphospholipid syndrome. Obstet Gynecol. 2012;120(6):1514-21.

16. Mantha S, Bauer KA, Zwicker JI. Low molecular weight heparin to achieve live birth following unexplained pregnancy loss: a systematic review. J Thromb Haemost. 2010;8(2):263-8.

17. Andersen AS, Berthelsen JG, Bergholt T. Venous thromboembolism in pregnancy: prophylaxis and treatment with low molecular weight heparin cta Obstet Gynecol. 2010;89:1515.

18. Tapson VF. Acute pulmonary embolism. N Engl J Med. 2008;358:1037.

19. Garcia DA, Spyropoulos AC. Update in the treatment of venous thromboembolism. Semin Respir Crit Care Med. 2008;29:40.

20. Leduc L, Dubois E, Takser L, Rey E, David M. Dalteparin and low-dose aspirin in the prevention of adverse obstetric outcomes in women with inherited thrombophilia. J Obstet Gynaecol Can. 2007;29(10):787-93.

21. McNamee K, Dawood F, Farquharson R. Recurrent miscarriage and thrombophilia: an update. Curr Opin Obstet Gynecol. 2012;24:229-34.

22. Regan L, Backos M, Rai. The investigation and treatment of couples with recurrent first trimester and second trimester miscarriages. RCOG Green-top Guideline No. 17. 2011;2011.

23. Cheung MW, Cheak AA, Ho RC. Combination of heparin and aspirin is superior to aspirin alone in enhancing live births in patients with recurrent pregnancy loss and positive anti-phospholipid antibodies: a meta-analysis of randomized controlled trials and meta-regression. Rheumatol 2010;49(2):2818.

24. Giannakpoulos B, Krilis SA. The pathogenesis of the antiphospholipid syndrome. $\mathrm{N}$ Engl $\mathrm{J}$ Med. 2013;368:1033.

25. Committee on Practice Bulletins-Obstetrics, American College of Obstetricians and Gynecologists. Practice Bulletin No. 132: Antiphospholipid syndrome. Obstet Gynecol. 2012;120(6):1514-21.

26. Erkan D, Kozora E, Lockshin MD. Cognitive dysfunction and white matter abnormalities in antiphospholipid syndrome. Pathophysiology. 2011;18(1):93.

27. Branch DW, Gibson M, Silver RM. Recurrent miscarriage. N Engl J Med. 2010;363:18.

Cite this article as: Asthana S, Sodhi B, Kumar S.

Obstetric outcomes in pregnancy with thrombophilia: a comparative study of two different

thromboprophylaxis regimes. Int J Reprod

Contracept Obstet Gynecol 2017;6:3882-6. 